\title{
A Novel Tabu Search Algorithm for Multi-AGV Routing Problem
}

\author{
Lining Xing ${ }^{1,2}$, Yuanyuan Liu ${ }^{2,3}{ }^{-}$, Haiyan $\mathrm{Li}^{3}$, Chin-Chia Wu ${ }^{4}{ }^{\oplus}$, Win-Chin $\operatorname{Lin}^{4}{ }^{\oplus}$ and \\ Xin Chen $5, *$ (D) \\ 1 School of Logistics, Central South University of Forestry and Technology, Changsha 410004, China; \\ xln_2002@nudt.edu.cn \\ 2 College of Systems Engineering, National University of Defense Technology, Changsha 410073, China; \\ liuyuanyuandream@gmail.com \\ 3 College of Computer Science and Engineering, Northeastern University, Shenyang 110819, China; \\ lihaiyan@mail.neu.edu.cn \\ 4 Department of Statistics, Feng Chia University, Taichung 40724, Taiwan; cchwu@fcu.edu.tw (C.-C.W.); \\ linwc@fcu.edu.tw (W.-C.L.) \\ 5 School of Electronics and Information Engineering, Liaoning University of Technology, \\ Jinzhou 121001, China \\ * Correspondence: chenxin@lnut.edu.cn
}

Received: 28 January 2020; Accepted: 14 February 2020; Published: 19 February 2020

\begin{abstract}
In this paper, we propose a novel tabu search (NTS) algorithm that improves the efficiencies of picking goods of automated guided vehicles (AGVs) in an automatic warehouse by solving the conflicts that happen when multiple AGVs work at the same time. Relocation and exchanging operations are designed for the neighborhood searching process based on each pickup-point's location in the warehouse, along with the initial solution generation and the termination condition in the proposed algorithm. The experimental results show that the tabu search algorithm can effectively optimize the order of pickup points, which could further reduce the total travel distance and improve the efficiencies of AGVs in automatic warehouses.
\end{abstract}

Keywords: automated guided vehicles (AGV); automatic warehouses; path optimization; tabu search

\section{Introduction}

Traditional warehouse management applies error-prone manual technology or limited applications of bar code technology. With the continuous development and application of Internet of Things (IOT) technology and network technology, the traditional warehouse management system is moving in an intelligent direction. The IOT recognizes and perceives objects through various smart sensors, and then data are transmitted to the information processing center that is specified through the network so that information can be automatically processed and exchanged throughout the world. When applied to warehousing, the IOT can monitor multiple processes, make everything connected to each other, and capture data that help to support decisions and improve overall performance [1]. With advantages such as saving space, reducing labor intensity, and improving the level of automation, automatic warehouses have been widely used in storage, inbound transportation, and outbound transportation processes in modern logistics products [2]. As one of the pieces of fully automated unmanned transport equipment, due to its high efficiency, flexibility, reliability, safety and system scalability [3], automated guided vehicles (AGVs) have become commonly-used pieces of transportation equipment in warehouse systems [4]. An AGV that is powered by batteries is usually guided by one or several combinations of electromagnetic, optical and laser navigation technologies, moving along an arranged path and having the function of avoiding collisions [5]. Order picking is the process of taking goods off a shelf according 
to a customer order and sending the goods out of the warehouse, either manually or mechanically [6-9] and categorized into picker-to-part picking and parts-to-picker picking [10]. Picker-to-parts picking means that the goods transportation equipment such as the AGV take the goods that correspond to the order from the shelf to the warehouse outlet. Packet-to-picker utilizes rotating shelves, vending machines, or conveyor belt systems to transport goods directly out of the warehouse or deliver the goods to the stop point where the transportation equipment waits to transport to the exit. In this study, we focused on the first problem. Researchers have found that the order picking process is estimated comprise approximately $55 \%$ of total warehouse operating expenses [11], and transportation time accounts for $50 \%$ of order picking time [12]. To increase competitiveness, globalized business companies must minimize costs for warehouse operations, which has led to a growing interest in warehouse management [13]. A reasonable access path of AGVs is conducive to the completion of goods loading and unloading in less time, which could reduce the distance and improve the efficiency of goods transportation. As a result, path optimization has been considered as one of the critical problems in AGV routing problems.

The access route problem was first proposed by Dantzig et al. [14] and could be considered as a routing problem arising from the sorting of goods on orders. In recent years, correlation research has abstracted this problem into the traveling salesman (TSP): Given a series of cities and the distance between each pair of cities, it will take different times for traveling salesmen to visit each city in different orders, so one must find the shortest route for traveling salesmen to visit each city only once and return to the starting city; this is an NP-hard (non-deterministic polynomial hard) problem in the field of combinatorial optimization [15]. Kelly and $\mathrm{Xu}$ [16] proposed a method of set partition to obtain high-quality path planning solutions. Fan et al. [17] used an ant colony algorithm to solve this problem. Combined with the Hopfield network model, Tian et al. [18] used the hybrid genetic algorithm to study the optimization of fixed shelf order-picking routing. Saska et al. [19] used particle swarm optimization. Zheng et al. [20] proposed the regional control method, which divides maps with multiple AGVs into several regions such that the driving regions of each AGV do not overlap. Zhang et al. [21] added turn times and the forward direction to the model of the cost function of AGV path optimization, and they improved the traditional A-Star $\left(\mathrm{A}^{*}\right)$ algorithm that is an extension of Dijkstra algorithm. Kim et al. [22] presented a guide containing illustration and comparison of the $\mathrm{A}^{*}$ algorithm and Dynamic $\mathrm{A}^{*}\left(\mathrm{D}^{*}\right)$ Lite algorithm that is a simplified version of the $\mathrm{D}^{*}$ algorithm applicable to the changing external environment: The $D^{*}$ Lite algorithm usually plans shorter paths faster than $\mathrm{A}^{*}$ algorithm does in large areas and complex work environments, while the $\mathrm{A}^{*}$ algorithm might be more effective than the $\mathrm{D}^{*}$ Lite algorithm in small areas and simple work environments. Zhang et al. [23] selected the corresponding strategy for different collision classifications, summarizing four collision classifications and proposing three solutions: selecting the candidate route, letting the later AGV wait before staring, and modifying the routes of the later AGV.

In the AGV routing problem, there is a distance between two pickup points, so the algorithm that is adopted to produce a large number of unreasonable orderings affects the performance of the algorithm. The population-based intelligent optimization algorithm has randomness, which may produce vast long-distance paths that are difficult to find and modify. Due to the ease of operation, the neighborhood-based intelligent optimization algorithm can be easily improved by changing its neighborhood structure according to the characteristics of the problem. Tabu search (TS) an intelligence-optimized algorithm based on neighborhoods that was first proposed by Fred Glover [24] and that is a search method that is used to find global optimal solutions. The algorithm is based on the improvement of local search algorithms, and a tabu list is introduced to overcome the disadvantage of falling into a local optimal during the search process, which results in a high possibility of global search. To the best of our knowledge, there has been no research concerned with a TS algorithm for the AGV routing problem.

Aiming at minimizing the total travel distance of an AGV, we propose a TS algorithm to optimize the general path for multiple AGVs working in automatic warehouses in this paper. We first analyze 
the conflicts that occur while multiple AGVs work at the same time, and then we design a suitable neighborhood search method to accelerate the convergence of the algorithm, all with the goal of path optimization. Finally, the performances of our algorithm are evaluated by simulation experiments.

The rest of this paper is organized as follows. The mathematical formulation of the multi-AGV routing optimization problem is given in Section 2, and the conflict types and solutions' representation are introduced in Section 3. Sections 4 and 5 are devoted to the design and analyses of our TS algorithm, and, finally, this paper is concluded in Section 6.

\section{Problem Formulation}

\subsection{Work Flow of Picking Up Goods}

A plane diagram of a common-used automatic warehouse is illustrated by the grid method [25] in Figure 1, which is divided into multiple rows and columns; each cell with the same size has been identified by its index. In order to make full use of ground resources, only one row or one column was designed for the transportation passageway, that is, the white areas in Figure 1 are the transportation passageways, while the gray ones are the locations of goods. Before working, all the AGVs are concentrated on the upper left corner (i.e., AGV1, AGV2 and AGV3 in Figure 1), and they then exit from the lower right corner (i.e., cell 150) when they finish the tasks. During the working process, the AGVs start from their initial locations, travel through the passageways to take the goods from shelves according to the orders, and finally deliver these goods to the exit.

\begin{tabular}{|c|c|c|c|c|c|c|c|c|c|c|c|c|c|c|}
\hline AGV1 & AGV2 & AGV3 & 4 & 5 & 6 & 7 & 8 & 9 & 10 & 11 & 12 & 13 & 14 & 15 \\
\hline 16 & 17 & 18 & 19 & 20 & 21 & 22 & 23 & 24 & 25 & 26 & 27 & 28 & 29 & 30 \\
\hline 31 & 32 & 33 & 34 & 35 & 36 & 37 & 38 & 39 & 40 & 41 & 42 & 43 & 44 & 45 \\
\hline 46 & 47 & 48 & 49 & 50 & 51 & 52 & 53 & 54 & 55 & 56 & 57 & 58 & 59 & 60 \\
\hline 61 & 62 & 63 & 64 & 65 & 66 & 67 & 68 & 69 & 70 & 71 & 72 & 73 & 74 & 75 \\
\hline 76 & 77 & 78 & 79 & 80 & 81 & 82 & 83 & 84 & 85 & 86 & 87 & 88 & 89 & 90 \\
\hline 91 & 92 & 93 & 94 & 95 & 96 & 97 & 98 & 99 & 100 & 101 & 102 & 103 & 104 & 105 \\
\hline 106 & 107 & 108 & 109 & 110 & 111 & 112 & 113 & 114 & 115 & 116 & 117 & 118 & 119 & 120 \\
\hline 121 & 122 & 123 & 124 & 125 & 126 & 127 & 128 & 129 & 130 & 131 & 132 & 133 & 134 & 135 \\
\hline 136 & 137 & 138 & 139 & 140 & 141 & 142 & 143 & 144 & 145 & 146 & 147 & 148 & 149 & $\begin{array}{c}150 \\
\text { Exit }\end{array}$ \\
\hline
\end{tabular}

Figure 1. Plane diagram of automatic warehouse. (Take three automated guided vehicles (AGVs) as examples, and cells 1-3 are their respective entrances.).

\subsection{Problem Description and Mathematical Formulation}

To solve a multi-AGV routing problem in an automatic warehouse, one usually adopts two-step process: (1) Determine the order of goods for each AGV, i.e., assign goods to different AGVs to sort the goods; (2) according to the order of the goods, calculate the shortest transport path among the pick-up points, entrances, and exit. It must be ensured that the AGVs can complete the given task, and, moreover, that there is no conflict within any pair of two AGVs in the transportation network.

The problem is based on the following assumptions:

(1) One only focuses on the issue of taking out goods, while the time of taking out goods is not counted.

(2) The number of AGVs is fixed.

(3) Since one only considers the case that the goods volume or quality is small enough and will not exceed the AGV capacity, the capacity limitations are ignored.

(4) One must consider each AGV as a particle with a constant velocity, regardless of turning time and acceleration.

(5) The starting and ending points of each AGV pickup path are the entrance and exit, respectively.

(6) Each pickup point is processed only once. 
(7) The distance to the adjacent cell is 1 , and the time taken to traverse that distance is 1.

The aim is to obtain the shortest transportation path to complete the order task. The path between any two points is directly arranged as the shortest path, and AGVs should not conflict with other AGVs in the process of driving.

The following notations are listed in Table 1 to describe the problem:

Table 1. Notations and meanings.

\begin{tabular}{cl}
\hline Notation & \multicolumn{1}{c}{ Meaning } \\
\hline $\mathrm{m}$ & The number of AGVs. \\
$\mathrm{n}$ & The number of pickup points. \\
$\mathrm{G}$ & A set of all cells. $\mathrm{G}=\{1, \ldots, \mathrm{g}\}$, where $\mathrm{g}$ is the number of cells. \\
$\mathrm{G}^{\prime}$ & A set of all goods which are waiting to be take out, $\mathrm{G}^{\prime} \subseteq \mathrm{G},\left|\mathrm{G}^{\prime}\right|=\mathrm{n}$. \\
$\mathrm{d}_{\mathrm{ij}}$ & Travel distance between pickup point (or entrance) $\mathrm{i}$ and pickup point (or exit) $\mathrm{j}$. \\
$\mathrm{r}_{\mathrm{i}}$ & The line number of the pickup location for the pickup point $\mathrm{i}$ or the line number of \\
& entrance and exit. $\mathrm{r}_{\mathrm{i}} \in[1, \mathrm{r}]$, and there are $\mathrm{r}$ rows. \\
$\mathrm{c}_{\mathrm{i}}$ & The column number of the pickup location for the pickup point $\mathrm{i}$ or the column number of \\
$\mathrm{x}_{\mathrm{ijk}}$ & entrance and exit. $\mathrm{c}_{\mathrm{i}} \in[1, \mathrm{c}]$, and there are columns.
\end{tabular}

Due to the layout characteristics of the automatic warehouse, the value of $d_{i j}$ can be calculated as follows, where $\left(\mathrm{p}_{1}, \mathrm{p}_{2}\right)$ indicates the driving path from point $\mathrm{p}_{1}$ to point $\mathrm{p}_{2}$. Some examples are shown in Figure 2.

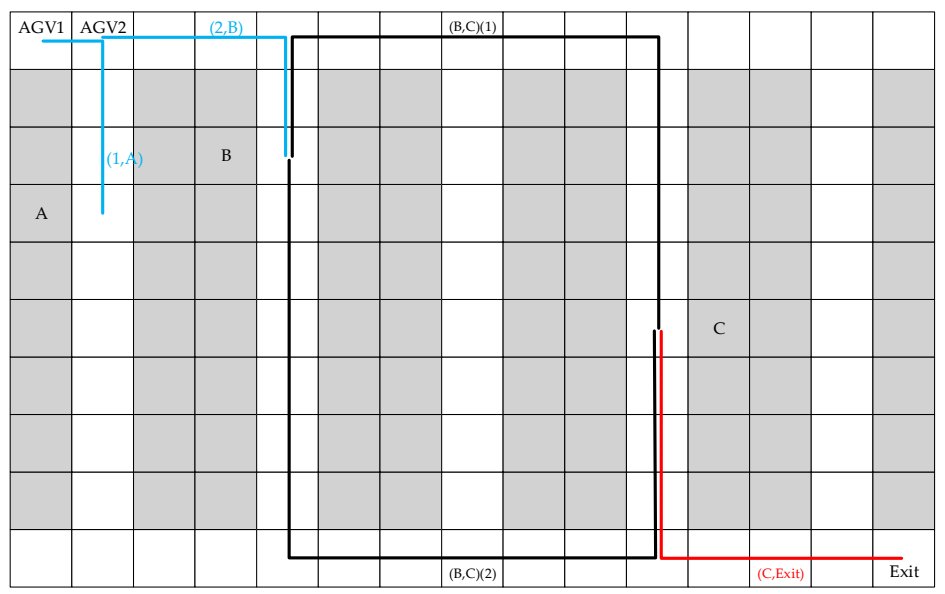

Figure 2. Examples of calculation method for the travel distance between pickup point (or entrance) $\mathrm{i}$ and pickup point (or exit) $\mathrm{j}\left(\mathrm{d}_{\mathrm{ij}}\right)$.

(1) The distance from the entrance i to the pickup point $\mathrm{j}$ :

$$
d_{i j}=\left\{\begin{array}{l}
\left(c_{j}-c_{i}\right)+\left(r_{j}-r_{i}\right), c_{i}<c_{j} \\
\left(c_{i}-c_{j}\right)+\left(r_{j}-r_{i}\right), c_{i}>c_{j}
\end{array}\right.
$$

Path $(1, A)$ and path $(2, B)$ show the cases when $c_{i}<c_{j}$.

(2) The distance from the pickup point $\mathrm{i}$ to the pickup point $\mathrm{j}$ :

If $c_{i} \neq c_{j}$ :

$$
d_{i j}=\left\{\begin{array}{l}
\min \left\{\left(c_{j}-c_{i}\right)+\left(r_{j}-1+r_{i}-1\right),\left(c_{j}-c_{i}\right)+\left(c-r_{j}+c-r_{i}\right)\right\}, c_{i}<c_{j} \\
\min \left\{\left(c_{i}-c_{j}\right)+\left(r_{j}-1+r_{i}-1\right),\left(c_{i}-c_{j}\right)+\left(c-r_{j}+c-r_{i}\right)\right\}, c_{i}>c_{j}
\end{array}\right.
$$


Otherwise:

$$
d_{i j}=\left\{\begin{array}{l}
r_{j}-r_{i}, r_{i}<r_{j} \\
r_{i}-r_{j}, r_{i} \geq r_{j}
\end{array}\right.
$$

Path $(B, C)$ shows the case when $c_{i}<c_{j}$. The shortest path between the paths of two driving directions $(B, C)(1)$ and $(B, C)(2)$ is chosen.

(3) The distance from the pickup point $\mathrm{i}$ to the entrance $\mathrm{j}$ :

$$
\mathrm{d}_{\mathrm{ij}}=\left(\mathrm{r}_{\mathrm{j}}-\mathrm{r}_{\mathrm{i}}\right)+\left(\mathrm{c}_{\mathrm{j}}-\mathrm{c}_{\mathrm{i}}\right)
$$

Path (C, Exit) shows this case.

According to the above description, the mathematical programming model of the problem can be obtained as follows:

$$
\text { Minimize } Z=\sum_{i=1}^{g} \sum_{j=1}^{g} \sum_{k=1}^{m} d_{i j} x_{i j k}+\sum_{i=1}^{g} \sum_{k=1}^{m} d_{k i} x_{k i k}+\sum_{i=1}^{g} \sum_{k=1}^{m} d_{i g} x_{i g k}\left(i \neq j, i, j \in G^{\prime}\right)
$$

Subject to:

$$
\begin{gathered}
\mathrm{x}_{\mathrm{ikk}}=0, \forall \mathrm{i} \in \mathrm{G}^{\prime}, \mathrm{k}=1,2, \ldots, \mathrm{m} \\
\mathrm{x}_{\mathrm{gik}}=0, \forall \mathrm{i} \in \mathrm{G}^{\prime}, \mathrm{k}=1,2, \ldots, \mathrm{m} \\
\mathrm{x}_{\mathrm{gkk}}=0, \forall \mathrm{k}=1,2, \ldots, \mathrm{m} \\
\sum_{\mathrm{i}=1}^{\mathrm{g}} \sum_{\mathrm{k}=1}^{\mathrm{m}} \mathrm{x}_{\mathrm{iik}}=0 \\
\sum_{\mathrm{i}=1}^{\mathrm{g}} \sum_{\mathrm{j}=1}^{\mathrm{g}} \sum_{\mathrm{k}=1}^{\mathrm{m}} \mathrm{x}_{\mathrm{ijk}}=1, \mathrm{j} \in \mathrm{G}^{\prime} \\
\sum_{\mathrm{k}=1}^{\mathrm{m}} \mathrm{x}_{\mathrm{kgk}}=0
\end{gathered}
$$

The objective is represented by Equation (1), which minimizes the total travel distance. Equations (2)-(4), respectively, indicate that in the AGV pickup sequence, the AGV cannot return to the entrance from the pickup point, go to any pickup point from the exit, or go to any entrance from the exit. Equation (5) limits the AGV not to stay at a point after visiting it. Equation (6) restricts the route so that each pickup point is visited only once. Equation (7) states that at least one pickup point should be arranged for each AGV.

\section{Conflict Types and Solving Approaches}

According to the driving direction of an AGV when a conflict occurs in the path planning process, the conflicts can be divided into two types.

\subsection{Opposite Direction Conflict}

The opposite direction conflict is the conflict between two AGVs that meet at the same location while running in opposite directions, so they collide with each other. The solution is to swap the subsequent pickup points when two AGVs collide. Figures 3 and 4 show an example. Suppose there is an opposite direction conflict between path A1-A2-A3 and path B1-B2-B3 and the conflict point is at the yellow cell where two AGVs arrive at the same time. Two pickup point sequences and corresponding driving paths before and after eliminating conflicts are shown. The total distance is reduced due to the reduction of overlapping sections. 

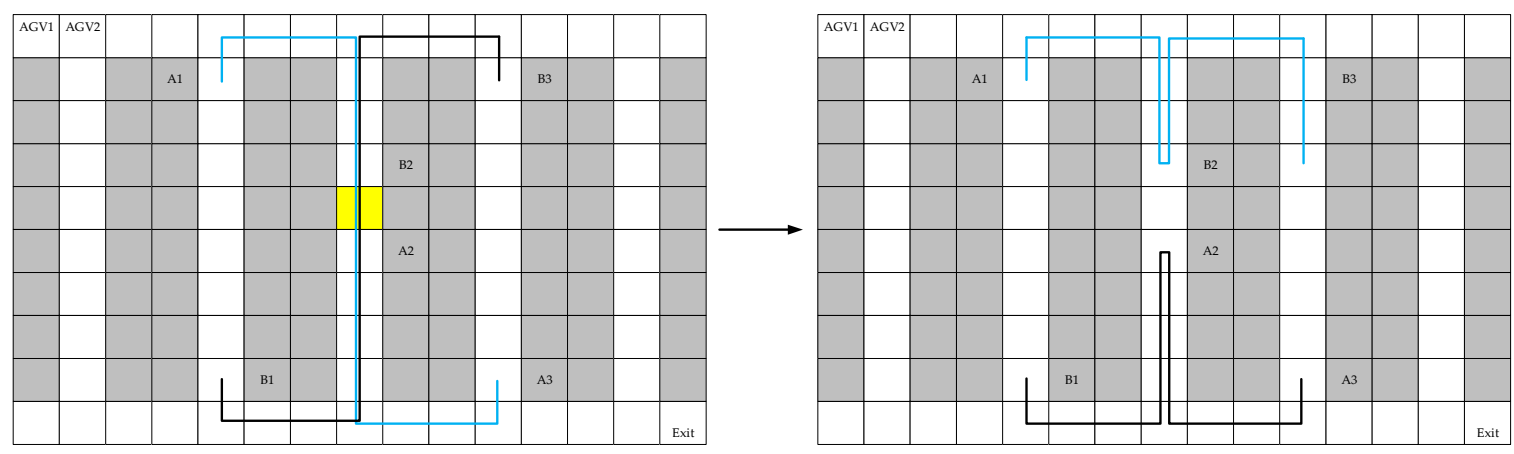

Figure 3. Driving paths before and after eliminating conflicts in opposite direction conflict.

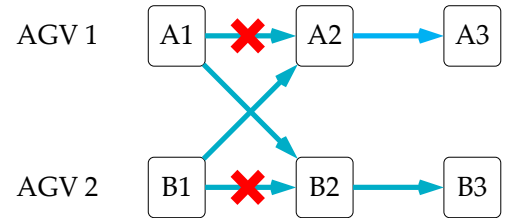

Figure 4. Pickup points sequences before and after eliminating conflicts in opposite direction conflict.

\subsection{Uniform Direction Conflict}

The uniform direction conflict is the conflict between two AGVs that meet at the same location while running in same direction, so they collide with each other. The solution is that one AGV waits for time 1, and the AGV that takes shorter time to pass the subsequent path is selected to wait. Figure 5 shows an example: Two AGVs go to right after meeting, and the conflict point is at the yellow cell. Since the subsequent pickup points of each AGV are already arranged when the algorithm runs, the AGV with the shortest time to run the subsequent path can be calculated, and its kept waiting time is 1 . For the sake of convenience, we also classified a further conflict that is caused by waiting after solving uniform conflicts as such.

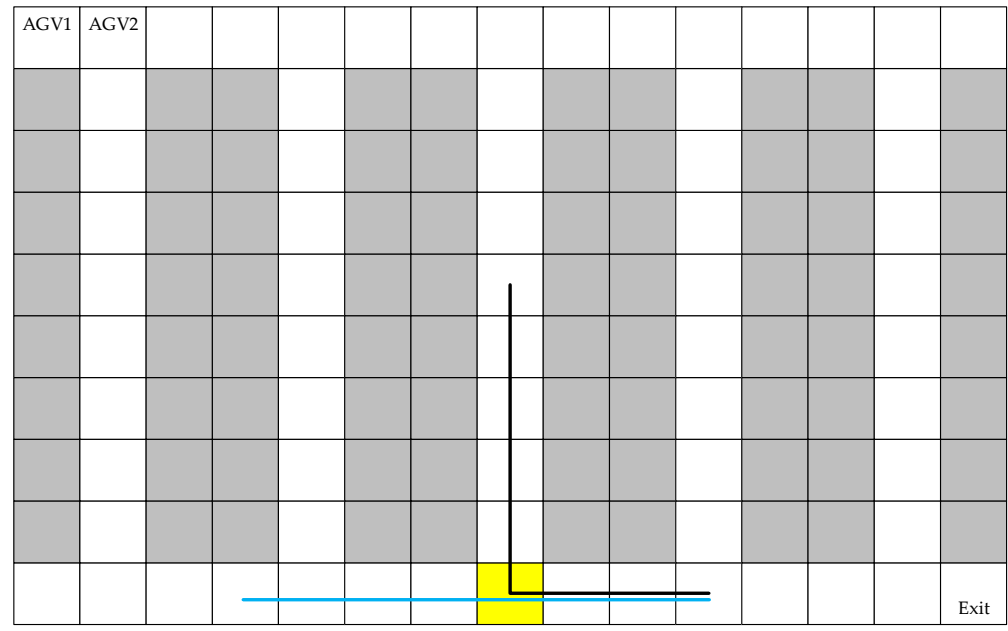

Figure 5. Uniform direction conflict when two AGVs meet at the yellow cell and are arranged to go to right. 


\section{Tabu Search Algorithm}

\subsection{Initial Solution Generation}

The method of generating the initial solution is an improvement on the nearest neighbor method:

(1) First, arrange the first pickup point for each AGV as the one that is closest to the AGV's entrance.

(2) Arrange the next nearest pickup point for the AGVs that takes shortest time to pick up all arranged goods.

(3) Arrange exit after all pickup points have been arranged.

There may be more than one AGV waiting to be arranged in processes (1) and (2), so if some AGVs want to select the same pickup point, the pickup point is assigned to the nearest AGV. In the above process, conflicts need to be checked and dealt with every time a pickup point or exit is arranged.

\subsection{Neighborhood Search}

We propose a relocation operation and exchanging operation combined with the pickup location of a pickup point. Before every iteration begins, the pickup point sequence of each AGV in the current solution is grouped: Entrances and the exit are grouped separately, and consecutive pickup points that are undertaken at same pickup passageway are divided into a group. Figure 6 shows an example of the grouping results, where the column number of passageway is marked in blue and the warehouse is designed to house 600 cells (20 rows and 30 columns).

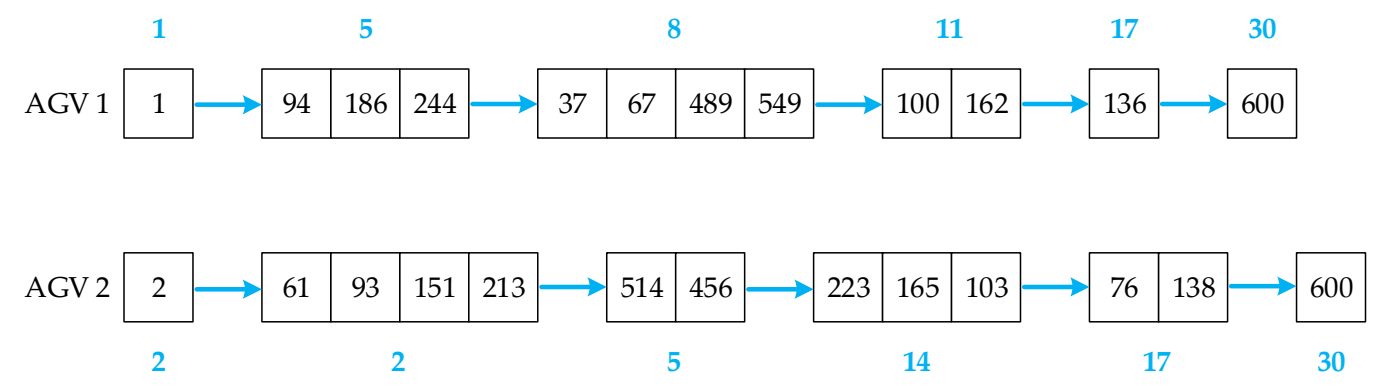

Figure 6. Grouping results for two AGVs' picking sequences in which every group is separated by an arrow.

\subsubsection{Relocation Operation}

The relocation operation is to move a group of pickup points from one AGV to another AGV.

The group of pickup points can be spilt by drawing a line between two adjacent points, and then one part can be inserted into another AGV sequence. Figure 7 shows all optional relocation sequences for a group of pickup points. 


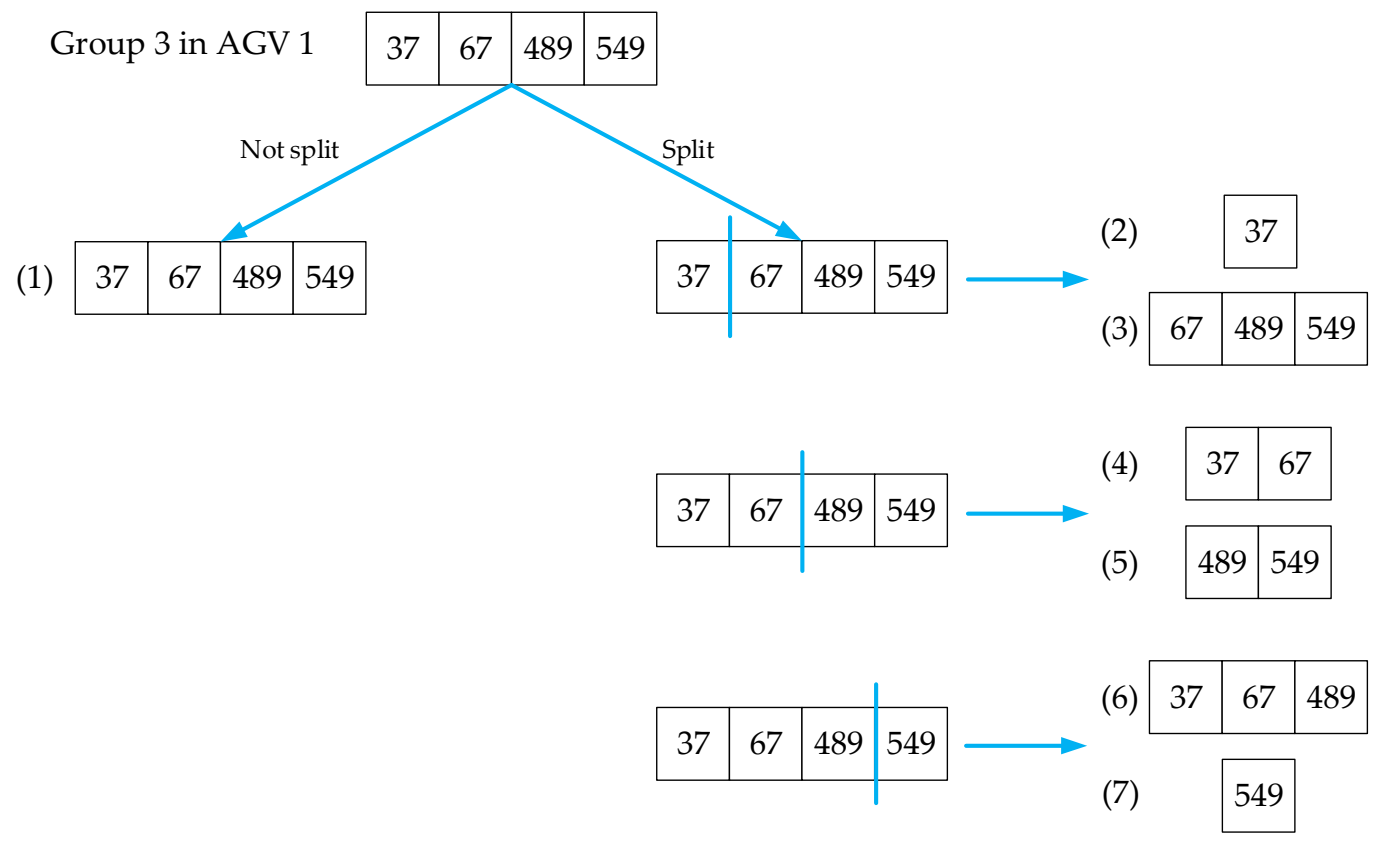

Figure 7. Optional relocation sequences including (1)-(7) in group 3 in AGV 1.

If another AGV has a group whose passageway number is same, the relocation sequence is combined into the group. Then, the combined sequence is sorted from the smallest to the largest, and the opposite sequence becomes another candidate solution. Figure 8 shows an example of this case: Group 2 in AGV 1 (not be split) is relocated into group 3 in AGV 2.

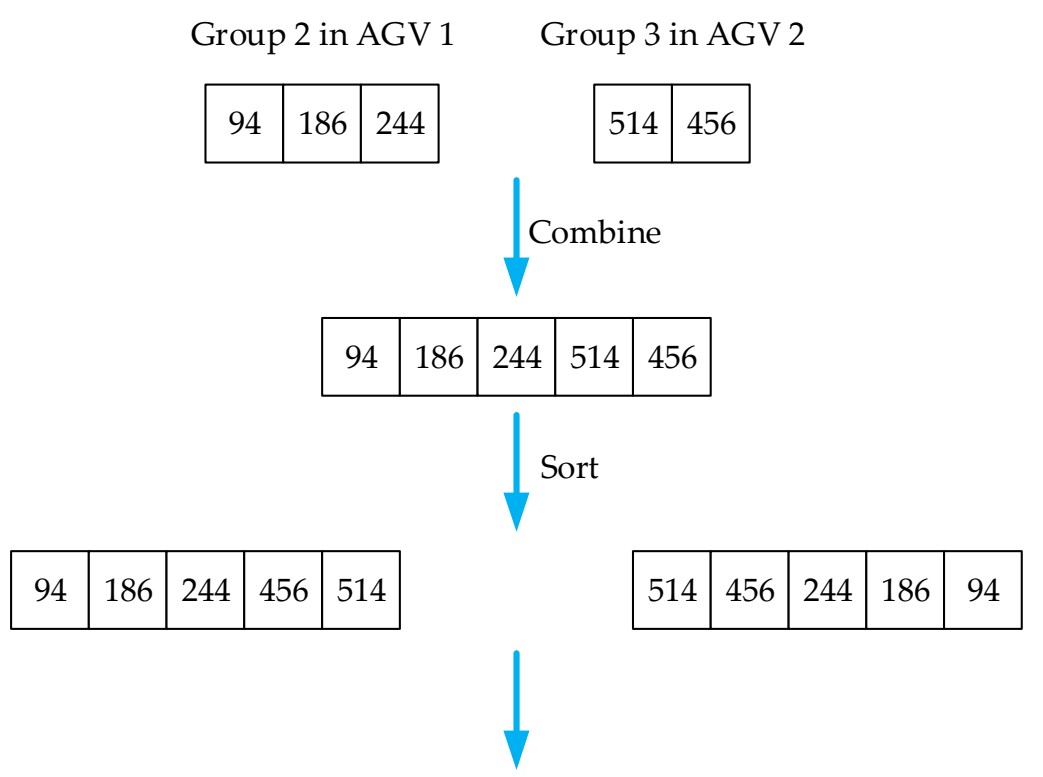

Two sequences are placed in the original position of group 3 in AGV 2 as two candidate solutions.

Figure 8. An example in a relocation operator when group 2 in AGV 1 (not be split) is relocated into group 3 in AGV 2.

If another AGV has no group whose passageway number is same, the relocation sequence is relocated into a proper location. Suppose the passageway column number of the relocation sequence 


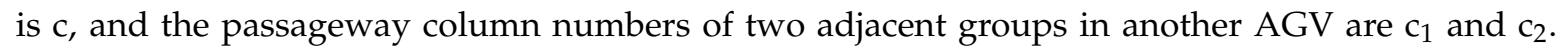
The relocation location satisfies the following condition:

$$
\mathrm{c} \in\left[\min \left\{\mathrm{c}_{1}, \mathrm{c}_{2}\right\}, \max \left\{\mathrm{c}_{1}, \mathrm{c}_{2}\right\}\right)
$$

For example, group 3 in AGV 1 can be relocated to the location between groups 3 and 4 in AGV 2. The split method and the order of relocating are similar.

\subsubsection{Exchanging Operation}

The exchanging operation is used to exchange a group of pickup points in two AGVs. Suppose that there are three continuous groups at passageway column number $c_{1}, c_{2}, c_{3}$ in AGV 1 and three continuous groups at passageway column number $c_{4}, c_{5}, c_{6}$ in AGV 2 . If a group at passageway number $c_{2}$ in AGV 1 can be exchanged with group at passageway column number $c_{5}$ in AGV 2 and there are no groups at passageway column number $c_{5}$ in AGV 1 and no groups at passageway number $c_{2}$ in AGV 2, the swapped locations should satisfy the following conditions:

$$
\begin{aligned}
& \mathrm{c}_{2} \in\left[\min \left\{\mathrm{c}_{4}, \mathrm{c}_{6}\right\}, \max \left\{\mathrm{c}_{4}, \mathrm{c}_{6}\right\}\right) \\
& \mathrm{c}_{5} \in\left[\min \left\{\mathrm{c}_{1}, \mathrm{c}_{3}\right\}, \max \left\{\mathrm{c}_{1}, \mathrm{c}_{3}\right\}\right)
\end{aligned}
$$

For example, the group at passageway column number 11 in AGV 1 can be exchanged with the group at passageway number 14 in AGV 2. Then two exchanged sequences are sorted and reversed to be candidate solutions, which are similar to those designed in the relocation operation.

\subsection{Tabu Object and Aspiration Criterion}

The tabu object is the objective function value. If all candidate solutions are tabooed in one of the iterations, the candidate solution with the best objective function value breaks the ban.

\subsection{Flow Chart of our TS Algorithm}

The tabu object is the objective function value. If all candidate solutions are tabooed in one of the iterations, the candidate solution with the best objective function value breaks the ban.

The concrete procedures of the novel tabu search (NTS) algorithm are expressed as follows.

Step 1: Set parameters, such as tabu list length (TL) and maximum number of iterations ( $\left.\tau_{\max }\right)$. The tabu list is set to be empty.

Step 2: Generate the initial solution by using an improved nearest neighbor method. Set the generation as $\tau=0$.

Step 3: Use improved relocation and exchange operators to generate candidate solution sets. If all candidates are tabooed, go to step 4; otherwise go to step 5 .

Step 4: The best solution of candidate solution set breaks the ban and is selected as the current solution. Then, go to step 6 .

Step 5: Select the best solution in the candidate solution set that is not tabooed as the current solution. Then, go to step 6 .

Step 6: If $\tau<\tau \max$, set $\tau=\tau+1$, then return to Step 3. Otherwise, go to Step 7 .

Step 7: Output the best solution and stop.

The flowchart of the NTS algorithm is shown in Figure 9. 


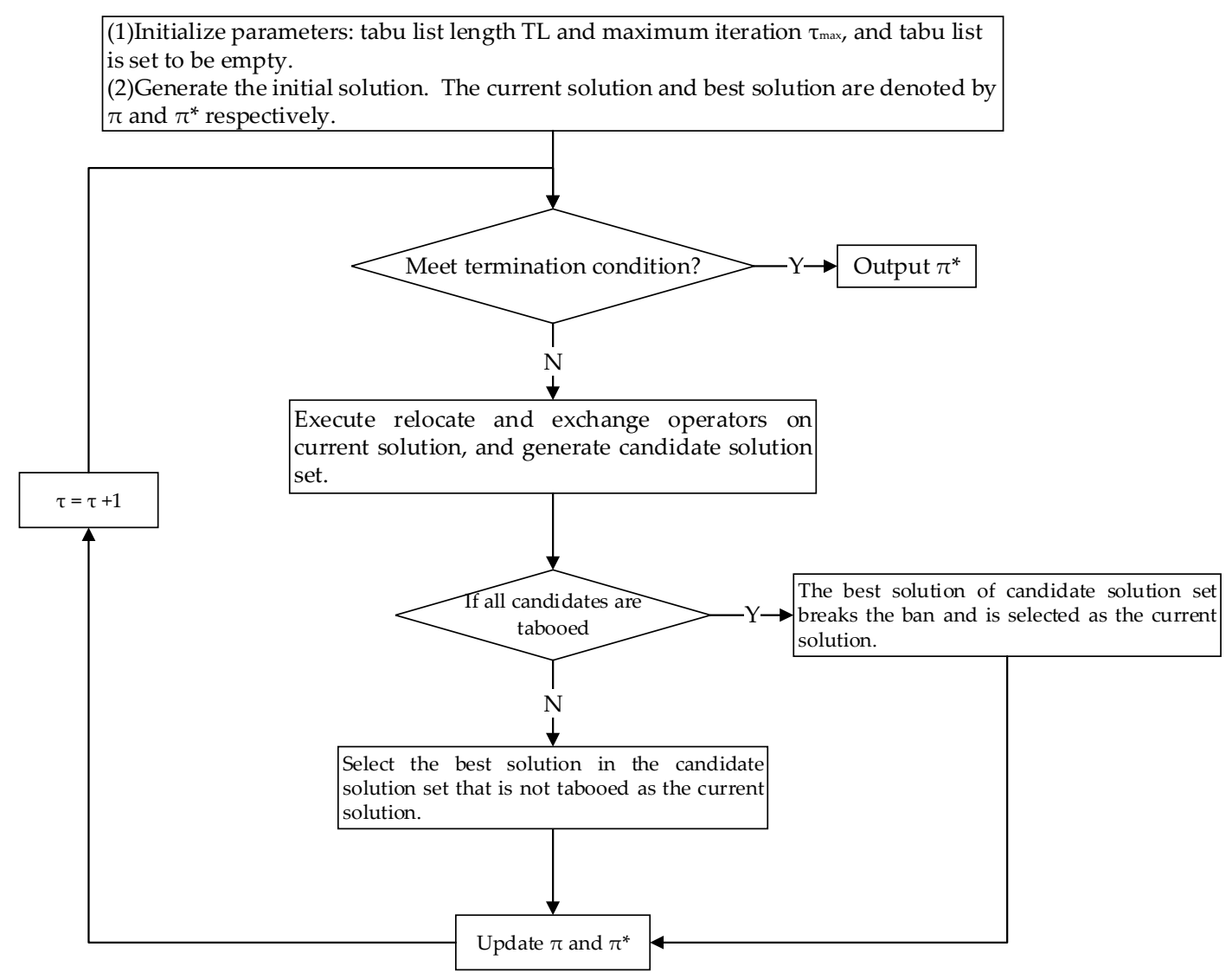

Figure 9. Novel tabu search (NTS) algorithm flowchart.

\section{Computational Results}

In the simulation experiment, the warehouse is divided into 600 cells (20 rows and 30 columns). The relevant control parameters of the algorithm are measured by the orthogonal test design method: a tabu list length of 7 and a maximum number of iterations of 100. The specific process of the orthogonal experimental design of the NTS algorithm is shown in Appendix A. Nine combinations of $n=60,100$, and 140 and $m=3,5$, and 8 were tested. Each combination tested 10 groups of random data and recorded the final objective function value. All algorithms were coded in $\mathrm{C}++$ programming language and implemented on a PC with an Intel Core i5 CPU $(1.6 \mathrm{GHz} \times 4)$ and 4 GB RAM.

As shown in Tables 2 and 3, the proposed algorithm (NTS) was compared with two algorithms. Compared with the TS algorithm that used the classical relocation and exchange operators, the NTS algorithm was superior in more than $90 \%$ of cases, which proves that the NTS algorithm design is reasonable. Compared with the differential evolution algorithm with a local search strategy (HDDE), from the average running time of each group of experiments, the NTS algorithm ran between 1.942 and $26.734 \mathrm{~s}$, the TS algorithm ran between 3.363 and $37.424 \mathrm{~s}$ (and was always slower than the NTS algorithm), while the HDDE algorithm could not get a solution in $60 \mathrm{~s}$. The relative improvement percentage GAP was employed to measure the performance of the NTS algorithm. The GAP can be calculated by Equation (8):

$$
\mathrm{GAP}=\frac{Z^{\mathrm{HDDE}}-\mathrm{Z}^{\mathrm{NTS}}}{\mathrm{Z}^{\mathrm{NTS}}} \times 100 \%,
$$

where $\mathrm{Z}^{\mathrm{NTS}}$ denotes the average final objective value of the NTS algorithm and $\mathrm{Z}^{\mathrm{HDDE}}$ denotes the average final objective value obtained by the HDDE algorithm. Figure 10 shows the trend of the average GAP values. 
Table 2. Computational results of the NTS algorithm, tabu search (TS) algorithm, and differential evolution algorithm with a local search strategy (HDDE) regarding the final objective value.

\begin{tabular}{|c|c|c|c|c|c|c|c|c|c|c|}
\hline & & \multicolumn{3}{|c|}{$n=60$} & \multicolumn{3}{|c|}{$n=100$} & \multicolumn{3}{|c|}{$n=140$} \\
\hline & & NTS & TS & HDDE & NTS & TS & HDDE & NTS & TS & HDDE \\
\hline \multirow{11}{*}{$m=3$} & Trail 1 & 281 & 283 & 387 & 277 & 281 & 431 & 285 & 367 & 487 \\
\hline & Trail 2 & 277 & 277 & 359 & 283 & 295 & 445 & 283 & 369 & 407 \\
\hline & Trail 3 & 271 & 277 & 385 & 281 & 289 & 367 & 285 & 357 & 481 \\
\hline & Trail 4 & 279 & 299 & 383 & 283 & 325 & 391 & 281 & 371 & 467 \\
\hline & Trail 5 & 279 & 293 & 371 & 281 & 285 & 429 & 283 & 297 & 409 \\
\hline & Trail 6 & 275 & 305 & 369 & 283 & 301 & 487 & 281 & 363 & 483 \\
\hline & Trail 7 & 275 & 299 & 403 & 281 & 319 & 419 & 285 & 327 & 477 \\
\hline & Trail 8 & 281 & 285 & 381 & 277 & 293 & 387 & 285 & 313 & 467 \\
\hline & Trail 9 & 275 & 275 & 377 & 283 & 293 & 483 & 285 & 331 & 477 \\
\hline & Trail 10 & 273 & 307 & 355 & 283 & 293 & 415 & 285 & 365 & 483 \\
\hline & average & 277 & 290 & 377 & 281 & 297 & 425 & 284 & 346 & 464 \\
\hline \multirow{11}{*}{$m=5$} & Trail 1 & 332 & 332 & 488 & 328 & 382 & 576 & 336 & 408 & 600 \\
\hline & Trail 2 & 328 & 340 & 466 & 334 & 454 & 556 & 334 & 418 & 612 \\
\hline & Trail 3 & 324 & 334 & 428 & 330 & 370 & 546 & 336 & 360 & 632 \\
\hline & Trail 4 & 330 & 326 & 488 & 334 & 438 & 582 & 332 & 380 & 612 \\
\hline & Trail 5 & 330 & 332 & 506 & 332 & 370 & 572 & 334 & 380 & 614 \\
\hline & Trail 6 & 332 & 344 & 466 & 332 & 340 & 554 & 332 & 388 & 638 \\
\hline & Trail 7 & 326 & 402 & 508 & 332 & 376 & 628 & 336 & 344 & 632 \\
\hline & Trail 8 & 328 & 344 & 446 & 330 & 410 & 514 & 336 & 384 & 624 \\
\hline & Trail 9 & 326 & 348 & 444 & 332 & 362 & 574 & 336 & 370 & 620 \\
\hline & Trail 10 & 324 & 344 & 462 & 334 & 382 & 552 & 336 & 400 & 648 \\
\hline & average & 328 & 345 & 470 & 332 & 388 & 565 & 335 & 383 & 623 \\
\hline \multirow{11}{*}{$m=8$} & Trail 1 & 394 & 432 & 522 & 394 & 482 & 694 & 394 & 510 & 698 \\
\hline & Trail 2 & 394 & 422 & 540 & 394 & 448 & 676 & 394 & 498 & 742 \\
\hline & Trail 3 & 392 & 430 & 526 & 406 & 464 & 680 & 394 & 528 & 866 \\
\hline & Trail 4 & 394 & 394 & 534 & 394 & 460 & 714 & 394 & 478 & 694 \\
\hline & Trail 5 & 394 & 466 & 530 & 394 & 496 & 676 & 394 & 474 & 712 \\
\hline & Trail 6 & 394 & 414 & 512 & 394 & 474 & 616 & 394 & 468 & 758 \\
\hline & Trail 7 & 394 & 420 & 558 & 394 & 488 & 668 & 394 & 510 & 710 \\
\hline & Trail 8 & 394 & 422 & 514 & 394 & 464 & 716 & 394 & 536 & 786 \\
\hline & Trail 9 & 394 & 432 & 484 & 394 & 488 & 700 & 394 & 516 & 742 \\
\hline & Trail 10 & 394 & 402 & 534 & 394 & 460 & 686 & 424 & 470 & 720 \\
\hline & average & 394 & 423 & 525 & 395 & 472 & 683 & 397 & 499 & 743 \\
\hline
\end{tabular}

Table 3. Computational results of the NTS, TS and HDDE algorithms regarding running time(s).

\begin{tabular}{|c|c|c|c|c|c|c|c|c|c|c|}
\hline & & \multicolumn{3}{|c|}{$n=60$} & \multicolumn{3}{|c|}{$n=100$} & \multicolumn{3}{|c|}{$n=140$} \\
\hline & & NTS & TS & HDDE & NTS & TS & HDDE & NTS & TS & HDDE \\
\hline \multirow{11}{*}{$m=3$} & Trail 1 & 1.951 & 3.079 & 500.397 & 3.715 & 8.128 & 10393.339 & 6.934 & 19.609 & $18,961.581$ \\
\hline & Trail 2 & 1.976 & 3.340 & 481.716 & 4.195 & 7.505 & 6626.229 & 6.913 & 19.374 & $15,427.298$ \\
\hline & Trail 3 & 1.939 & 3.246 & 575.057 & 3.926 & 8.440 & 3634.481 & 7.386 & 17.116 & $24,877.259$ \\
\hline & Trail 4 & 1.948 & 3.393 & 435.070 & 3.929 & 8.798 & 5256.536 & 6.945 & 19.320 & $19,682.740$ \\
\hline & Trail 5 & 1.945 & 2.994 & 727.229 & 4.019 & 7.853 & 3738.185 & 7.169 & 14.811 & $16,561.710$ \\
\hline & Trail 6 & 2.097 & 3.653 & 892.122 & 3.979 & 8.063 & 3964.789 & 6.895 & 18.527 & $22,405.243$ \\
\hline & Trail 7 & 1.920 & 3.544 & 472.420 & 3.963 & 8.769 & 3698.056 & 7.130 & 17.053 & $16,051.987$ \\
\hline & Trail 8 & 1.836 & 3.504 & 506.553 & 4.180 & 8.235 & 4511.152 & 6.800 & 15.419 & $17,810.505$ \\
\hline & Trail 9 & 1.921 & 3.619 & 526.601 & 3.937 & 8.293 & 5317.399 & 6.803 & 16.498 & $21,293.276$ \\
\hline & Trail 10 & 1.882 & 3.255 & 610.396 & 3.957 & 8.216 & 4840.318 & 6.902 & 16.684 & $19,258.136$ \\
\hline & average & 1.942 & 3.363 & 572.756 & 3.980 & 8.230 & 5198.048 & 6.988 & 17.441 & $19,232.974$ \\
\hline
\end{tabular}


Table 3. Cont.

\begin{tabular}{|c|c|c|c|c|c|c|c|c|c|c|}
\hline & & \multicolumn{3}{|c|}{$n=60$} & \multicolumn{3}{|c|}{$n=100$} & \multicolumn{3}{|c|}{$n=140$} \\
\hline & & NTS & TS & HDDE & NTS & TS & HDDE & NTS & TS & HDDE \\
\hline \multirow{11}{*}{$m=5$} & Trail 1 & 3.943 & 5.118 & 1512.533 & 8.161 & 13.505 & 8391.081 & 13.857 & 25.214 & $23,283.422$ \\
\hline & Trail 2 & 3.744 & 5.729 & 1118.698 & 8.226 & 15.769 & 5361.342 & 14.364 & 25.011 & $25,869.500$ \\
\hline & Trail 3 & 4.162 & 5.285 & 1415.852 & 8.122 & 12.086 & 6211.561 & 13.974 & 22.084 & $19,439.788$ \\
\hline & Trail 4 & 3.847 & 5.137 & 1005.755 & 8.715 & 14.787 & 8971.270 & 13.817 & 23.234 & $19,355.222$ \\
\hline & Trail 5 & 3.943 & 5.283 & 1002.492 & 8.794 & 12.581 & 5422.703 & 14.377 & 23.769 & $32,212.212$ \\
\hline & Trail 6 & 4.175 & 5.018 & 1660.255 & 8.335 & 11.313 & 5428.650 & 13.936 & 23.018 & $27,777.053$ \\
\hline & Trail 7 & 3.781 & 6.661 & 1097.204 & 9.005 & 12.915 & 5506.001 & 14.149 & 20.961 & $18,425.203$ \\
\hline & Trail 8 & 3.926 & 5.121 & 747.236 & 9.171 & 13.433 & 7585.026 & 13.968 & 22.647 & $19,667.650$ \\
\hline & Trail 9 & 3.886 & 5.397 & 1090.556 & 8.063 & 13.870 & 6643.318 & 15.191 & 21.957 & $26,439.659$ \\
\hline & Trail 10 & 3.831 & 5.343 & 774.069 & 8.194 & 12.069 & 7663.535 & 15.621 & 24.568 & $36,381.835$ \\
\hline & average & 3.924 & 5.409 & 1142.465 & 8.479 & 13.233 & 6718.449 & 14.325 & 23.246 & $24,885.154$ \\
\hline \multirow{11}{*}{$m=8$} & Trail 1 & 7.909 & 8.179 & 3591.557 & 15.968 & 21.845 & 21426.231 & 26.412 & 37.348 & $65,224.116$ \\
\hline & Trail 2 & 7.944 & 9.163 & 1993.240 & 16.141 & 20.724 & 16625.712 & 27.428 & 37.365 & $52,793.295$ \\
\hline & Trail 3 & 7.439 & 8.678 & 2572.098 & 16.060 & 21.320 & 12983.184 & 26.943 & 38.875 & $40,496.482$ \\
\hline & Trail 4 & 7.476 & 8.928 & 2486.247 & 16.141 & 20.554 & 15421.759 & 26.965 & 37.227 & $58,480.069$ \\
\hline & Trail 5 & 7.427 & 9.956 & 5021.107 & 15.853 & 22.104 & 21253.317 & 26.223 & 35.783 & $37,094.787$ \\
\hline & Trail 6 & 7.735 & 9.127 & 4354.038 & 16.463 & 21.325 & 18642.408 & 26.408 & 35.057 & $59,505.527$ \\
\hline & Trail 7 & 7.310 & 9.180 & 1994.660 & 16.198 & 20.710 & 16229.108 & 26.940 & 37.375 & $37,644.008$ \\
\hline & Trail 8 & 7.694 & 9.268 & 6158.387 & 16.981 & 19.987 & 12600.642 & 27.410 & 40.199 & $47,251.975$ \\
\hline & Trail 9 & 7.676 & 9.435 & 6523.730 & 15.497 & 21.908 & 10957.605 & 26.486 & 39.158 & $36,420.641$ \\
\hline & Trail 10 & 7.538 & 9.511 & 5716.876 & 15.832 & 20.071 & 16501.993 & 26.127 & 35.850 & $77,484.502$ \\
\hline & average & 7.615 & 9.143 & 4041.194 & 16.113 & 21.055 & 16264.196 & 26.734 & 37.424 & $51,239.540$ \\
\hline
\end{tabular}

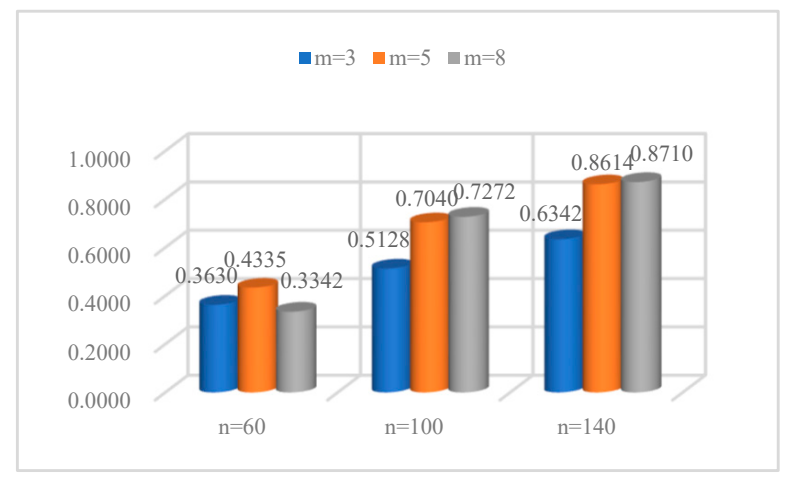

Figure 10. The average GAP concerning nine combinations of $n=60,100$, and 140 and $m=3,5$, and 8 .

The following can be observed from Figure 10. With the increase of the number of pickup points $n$, the average GAP value always became larger and larger. Because of the growing scale of the problem, the differences between the HDDE and NTS algorithms were clearer. With the rise of the number of AGVs m, the average GAP value went up when $n=100$ and 140, which was because the number of possible order combinations of pickup points enlarged. When $n=60$, the trend did not follow the same pattern, probably due to instability of the NTS algorithm. The high effectiveness of the NTS algorithm is indicated. By improving the neighborhood structure, our NTS algorithm operates on one or more adjacent points and moves them to a reasonable position in a good order to avoid increasing unnecessary path lengths. Thus, our NTS algorithm retains the advantages of the classic TS, with better improvements. However, the classical TS algorithm only operates on one pickup point in the neighborhood operator, which is less flexible than the NTS algorithm. The HDDE algorithm hopes to obtain a better solution by introducing a local search strategy, and the local search operation generates significant time consumption. Due to the randomness of the HDDE algorithm itself, a large number of long paths are generated, and good results cannot be obtained even at the cost of time. Long paths greatly affect the performance of good paths, so a good order cannot be preserved. Therefore, we found that because of the distance between each pair of pickup points in the AGV path problem, 
the ability to sort the pickup point is key to the performance of the algorithm. The NTS algorithm proposed in this paper solves this problem well and shows the advantage of an intelligent optimization algorithm that is based on neighborhoods, while an intelligent optimization algorithm that is based on population, like the HDDE, is not suitable for solving this problem.

\section{Conclusions}

Customer requirements are changing, and expectations are rising. Companies are also facing challenges from global competitors that offer customers a wide range of choices via the internet. Intelligent warehouses support enterprises in fierce market competition, overcoming challenges such as demand fluctuation [26]. The normal operation of the warehouse process is the basis of logistics supply chain improvement [27]. With the rapid development of warehouse logistics, the routing optimization of AGVs is playing an important role in improving the efficiency of goods selection and customer satisfaction, thus attracting much attention. An excellent AGV routing scheme can classify and deliver the orders of consumers earlier, which can greatly improve the experience and satisfaction of consumers [28]. The TS algorithm proposed in this article considers situations that may improve the current feasible solutions for designing neighborhood structures, eliminating bad feasible solutions, and accelerating the neighborhood search speeds. Finally, our numerical experiments indicated that this algorithm can improve calculation accuracy when solving the AGV routing problems. Compared with those employed in previous studies, our algorithm adopts conflict resolution methods that do not sacrifice distance, ensure the shortest distance between two points, and try to compress feasible regions to find excellent solutions faster. Therefore, we have found that for AGV path problems, neighborhood-based intelligent optimization algorithms are often more efficient than population-based intelligent optimization algorithms. The improved strategy used by the NTS algorithm that we have proposed $\mathrm{s}$ is effective and has strong applicability to AGV path optimization problems in real-life warehouse management.

The main limitation of the proposed algorithm is related to the assumptions that were made in its design process. Some warehouses have a large volume or a high quality of goods, so one AGV may not carry a lot during the actual warehousing process [29]. Once capacity constraints are taken into account, the number of AGVs in and out of storage increases, and the resolution of conflicts becomes more complex.

Due to the variability of such problems and the complexity of solving them, research on such problems is still continuing, and further research will focus on two directions: (1) The solving of multiple objectives optimization problems, such as reducing the maximum pickup time and the number of AGV used, in order to offer a wide range of solutions that represent a balance between objectives and Pareto-based strategies [30]; (2) the consideration of cases when the volume of goods exceeds the AGV 's capacity to adapt to the picking processes of different sizes of goods.

Author Contributions: Writing-original draft preparation, L.X.; methodology-designing algorithms, Y.L.; Conceptualization—problem modeling, H.L.; numerical analysis, C.-C.W.; writing—review and editing, W.-C.L.; supervision, X.C. All authors have read and agreed to the published version of the manuscript.

Funding: This work was supported in part by the National Natural Science Foundation of China (No. 61773120), Research Foundation of Liaoning (No. 2019-MS-170), Innovation Team of Guangdong Provincial Department of Education (2018KCXTD031) and Hunan Key Laboratory of Intelligent Logistics Technology (2019TP1015).

Acknowledgments: The authors appreciate the editors and three reviewers for their helpful comments on this paper.

Conflicts of Interest: The authors declare no conflict of interest.

\section{Appendix A}

Parameters setting for the NTS algorithm:

The two factors that influence the performance of the NTS algorithm were tested. The levels required to test for each factor are shown in Table A1, and the orthogonal experimental design table is 
shown in Table A2. Each group of experiment included 10 random tests, $n=60$, and the improved value of the algorithm was recorded. The Experimental Result column was the mean of 10 groups of improved values. The improved value $\frac{\mathrm{Z}^{\mathrm{OS}}-\mathrm{Z}^{\mathrm{FS}}}{\mathrm{Z}^{\mathrm{FS}}} \times 100 \%$, where $Z^{\mathrm{OS}}$ denotes the objective value of the initial solution and $Z^{\mathrm{FS}}$ denotes the final objective value obtained by the NTS algorithm, was employed.

Table A1. Orthogonal factor level table of the NTS algorithm.

\begin{tabular}{ccc}
\hline Factors & Tabu List Length & Maximum Number of Iterations \\
\hline Level 1 & 3 & 100 \\
Level 2 & 5 & 200 \\
Level 3 & 7 & 300 \\
Level 4 & & 400 \\
Level 5 & & 500 \\
\hline
\end{tabular}

Table A2. Orthogonal experimental design table of the NTS algorithm.

\begin{tabular}{|c|c|c|c|c|}
\hline Factors & & Tabu List Length & $\begin{array}{l}\text { Maximum Number of } \\
\text { Iterations }\end{array}$ & $\begin{array}{c}\text { Experimental } \\
\text { Result }\end{array}$ \\
\hline Trail 1 & & 3 & 100 & 40.85 \\
\hline Trail 2 & & 3 & 200 & 32.14 \\
\hline Trail 3 & & 3 & 300 & 30.39 \\
\hline Trail 4 & & 3 & 400 & 40.19 \\
\hline Trail 5 & & 3 & 500 & 34.39 \\
\hline Trail 6 & & 5 & 100 & 39.31 \\
\hline Trail 7 & & 5 & 200 & 37.40 \\
\hline Trail 8 & & 5 & 300 & 38.71 \\
\hline Trail 9 & & 5 & 400 & 31.89 \\
\hline Trail 10 & & 5 & 500 & 32.15 \\
\hline Trail 11 & & 7 & 100 & 41.57 \\
\hline Trail 12 & & 7 & 200 & 32.07 \\
\hline Trail 13 & & 7 & 300 & 39.07 \\
\hline Trail 14 & & 7 & 400 & 34.74 \\
\hline Trail 15 & & 7 & 500 & 35.37 \\
\hline Trail 16 & & 5 & 100 & 35.31 \\
\hline Trail 17 & & 5 & 200 & 37.67 \\
\hline Trail 18 & & 5 & 300 & 37.05 \\
\hline Trail 19 & & 5 & 400 & 36.64 \\
\hline Trail 20 & & 5 & 500 & 34.07 \\
\hline Trail 21 & & 5 & 100 & 36.28 \\
\hline Trail 22 & & 5 & 200 & 34.41 \\
\hline Trail 23 & & 5 & 300 & 41.39 \\
\hline Trail 24 & & 5 & 400 & 37.01 \\
\hline Trail 25 & & 5 & 500 & 36.66 \\
\hline \multirow{5}{*}{$\begin{array}{l}\mathrm{K}_{\mathrm{i}} \text { (Sum of experimental } \\
\text { results at level i) }\end{array}$} & $\mathrm{K}_{1}$ & 177.954 & 193.314 & - \\
\hline & $\mathrm{K}_{2}$ & 545.947 & 173.679 & - \\
\hline & $\mathrm{K}_{3}$ & 182.814 & 186.608 & - \\
\hline & $\mathrm{K}_{4}$ & - & 180.475 & - \\
\hline & $\mathrm{K}_{5}$ & - & 172.639 & - \\
\hline \multirow{5}{*}{$\begin{array}{c}\overline{\mathrm{K}_{\mathrm{i}}} \text { (Mean of experimental } \\
\text { results at level i) }\end{array}$} & $\overline{\mathrm{K}_{1}}$ & 35.591 & 38.663 & - \\
\hline & $\overline{\mathrm{K}_{2}}$ & 36.396 & 34.736 & - \\
\hline & $\overline{\mathrm{K}_{3}}$ & 36.563 & 37.322 & - \\
\hline & $\overline{\mathrm{K}_{4}}$ & - & 36.095 & - \\
\hline & $\overline{\mathrm{K}_{5}}$ & - & 34.528 & - \\
\hline
\end{tabular}


Table A3. Analysis of variance table of the NTS algorithm.

\begin{tabular}{|c|c|c|c|c|c|}
\hline $\begin{array}{l}\text { Sources of } \\
\text { Variation }\end{array}$ & $\begin{array}{c}\text { Sum of Squares of } \\
\text { Deviations }\end{array}$ & $\begin{array}{l}\text { Degree of } \\
\text { Freedom }\end{array}$ & Mean Square & $F$ Value & Significance \\
\hline Tabu list length & 2.975 & 2 & 1.488 & - & - \\
\hline $\begin{array}{l}\text { Maximum number } \\
\text { of iterations }\end{array}$ & 61.255 & 4 & 15.314 & - & - \\
\hline Error & 175.544 & 18 & 9.752 & - & - \\
\hline Total & 239.774 & 24 & - & - & - \\
\hline \multicolumn{6}{|c|}{ Incorporate the Factor Tabu List Length into the Error Column and Recalculate } \\
\hline $\begin{array}{l}\text { Sources of } \\
\text { Variation }\end{array}$ & $\begin{array}{c}\text { Sum of Squares of } \\
\text { Deviations }\end{array}$ & $\begin{array}{l}\text { Degree of } \\
\text { Freedom }\end{array}$ & Mean Square & F Value & Significance \\
\hline Tabu list length & 2.975 & 2 & 1.488 & - & No influence \\
\hline $\begin{array}{l}\text { Maximum number } \\
\text { of iterations }\end{array}$ & 61.255 & 4 & 15.314 & 1.716 & No influence \\
\hline Error & 178.519 & 20 & 8.926 & - & - \\
\hline Total & 239.774 & 24 & - & - & - \\
\hline
\end{tabular}

The variance analysis for the experimental results is shown in Table A3. According to the experimental data, the level of each factor is determined as a tabu list length of 7 and a maximum number of iterations of 100 .

(The error columns did not participate in the calculation, so those are not shown in Table A3.)

\section{References}

1. Mostafa, N.; Hamdy, W.; Alawady, H. Impacts of Internet of Things on supply chains: A framework for warehousing. Soc. Sci. 2019, 8, 84. [CrossRef]

2. Richards, G. Warehouse Management: A Complete Guide to Improving Efficiency and Minimizing Costs in the Modern Warehouse, 3rd ed.; Kogan Page: London, UK, 2017; pp. 7-25.

3. Moshayedi, A.J.; Li, J.; Liao, L. AGV (automated guided vehicle) robot: Mission and obstacles in design and performance. J. Simul. Anal. Nov. Technol. Mech. Eng. 2019, 12, 5-18.

4. Gotting, H.H. Automation and steering of vehicles in ports. Port Technol. Int. 2000, 10, 101-111.

5. Liu, J.E.; Zhang, S.; Liu, H. Research on AGV Path Planning under "Parts-to-Picker" Mode. Open J. Soc. Sci. 2019, 7, 1-14. [CrossRef]

6. Petersen, C.G.; Schmenner, R.W. An evaluation of routing and volume-based storage policies in an order picking operation. Decis. Sci. 1999, 30, 481-501. [CrossRef]

7. Roodbergen, K.J.; De Koster, R. Routing order pickers in a warehouse with a middle aisle. Eur. J. Oper. Res. 2001, 133, 32-43. [CrossRef]

8. Grosse, E.H.; Glock, C.H. The effect of worker learning on manual order picking processes. Int. J. Prod. Econ. 2015, 170, 882-890. [CrossRef]

9. Giannikas, V.; Lu, W.; Robertson, B.; McFarlane, D. An interventionist strategy for warehouse order picking: Evidence from two case studies. Int. J. Prod. Econ. 2017, 189, 63-76. [CrossRef]

10. Koo, P.H. The use of bucket brigades in zone order picking systems. OR Spectr. 2009, 31, 759. [CrossRef]

11. Koster, R.D.; Le-Duc, T.; Roodbergen, K.J. Design and control of warehouse order picking: A literature review. Eur. J. Oper. Res. 2007, 182, 481-501. [CrossRef]

12. Manzini, R. Warehousing in the Global Supply Chain; Springer: London, UK, 2012; pp. 104-137.

13. Yener, F.; Yazgan, H.R. Optimal warehouse design: Literature review and case study application. Comput. Ind. Eng. 2019, 129, 1-13. [CrossRef]

14. Dantzig, G.B.; Ramser, J.H. The truck dispatching problem. Manag. Sci. 1959, 6, 80-91. [CrossRef]

15. Qu, H.; Yi, Z.; Tang, H. A columnar competitive model for solving multi-traveling salesman problem. Chaos Solitons Fractals 2007, 31, 1009-1019. [CrossRef]

16. Kelly, J.P.; Xu, J. A set-partitioning-based heuristic for the vehicle routing problem. Inf. J. Comput. 1999, 11, 161-172. [CrossRef] 
17. Fan, X.; Luo, X.; Yi, S.; Yang, S.; Zhang, H. Optimal Path Planning for Mobile Robots Based on Intensified Ant Colony Optimization Algorithm. In Proceedings of the 2003 IEEE International Conference on Robotics, Intelligent Systems and Signal, Changsha, China, 8-13 October 2003.

18. Tian, G.; Zhang, P.; Li, X.; Yin, J.; Lu, F. Research on one class of optimization problem of the automated warehouse using a new kind of hybrid genetic algorithm. J. Syst. Simul. 2004, 16, 1198-1201.

19. Saska, M.; Macas, M.; Preucil, L.; Lhotska, L. Robot Path Planning Using Particle Swarm Optimization of Ferguson Splines. In Proceedings of the 2006 IEEE Conference on Emerging Technologies and Factory Automation, Prague, Czech Republic, 20-22 September 2006.

20. Zheng, K.; Tang, D.; Gu, W.; Dai, M. Distributed control of multi-AGV system based on regional control model. Prod. Eng. 2013, 7, 433-441. [CrossRef]

21. Zhang, B.; Li, L.; Zhao, Y.; Li, J. The Research on E-Commerce Logistics Picking AGV Path Optimization Method Based on the Improved A* Algorithm. In Proceedings of the 2016 International Conference on Cybernetics, Robotics and Control (CRC), Hong Kong, China, 19-21 August 2016.

22. Kim, D.H.; Hai, N.T.; Joe, W.Y. A Guide to Selecting Path Planning Algorithm for Automated Guided Vehicle (AGV). In Proceedings of the AETA 2017-Recent Advances in Electrical Engineering and Related Sciences: Theory and Application, Ho Chi Minh, Vietnam, 7-9 December 2017.

23. Zhang, Z.; Guo, Q.; Chen, J.; Yuan, P. Collision-free route planning for multiple agvs in automated warehouse based on collision classification. IEEE Access 2018, 6, 26022-26035. [CrossRef]

24. Glover, F. Future paths for integer programming and links to artificial intelligence. Comput. Oper. Res. 1986, 13, 533-549. [CrossRef]

25. Lee, T.K.; Baek, S.H.; Choi, Y.H.; Oh, S.Y. Smooth coverage path planning and control of mobile robots based on high-resolution grid map representation. Robot. Auton. Syst. 2011, 59, 801-812. [CrossRef]

26. Yerpude, S.; Singhal, T.K. SMART Warehouse with Internet of Things supported Inventory Management System. Int. J. Pure Appl. Math. 2018, 118, 1-15.

27. Habazin, J.; Glasnović, A.; Bajor, I. Order picking process in warehouse: Case study of dairy industry in Croatia. Promet-Traffic Trans. 2017, 29, 57-65. [CrossRef]

28. Liu, Y.; Ji, S.; Su, Z.; Guo, D. Multi-objective AGV scheduling in an automatic sorting system of an unmanned (intelligent) warehouse by using two adaptive genetic algorithms and a multi-adaptive genetic algorithm. PLoS ONE 2019, 14, e0226161. [CrossRef] [PubMed]

29. Zuniga, C.A.; Olivares-Benitez, E.; Tenahua, A.M.; Mujica, M.A. A methodology to solve the Order Batching Problem. IFAC-PapersOnLine 2015, 48, 1380-1386. [CrossRef]

30. Nosrati, M.; Khamseh, A. Bi objective hybrid vehicle routing problem with alternative paths and reliability. Decis. Sci. Lett. 2020, 9, 145-162. [CrossRef]

(C) 2020 by the authors. Licensee MDPI, Basel, Switzerland. This article is an open access article distributed under the terms and conditions of the Creative Commons Attribution (CC BY) license (http://creativecommons.org/licenses/by/4.0/). 